\title{
Phillip Vallentine Tobias (1925-2012)
}

\section{Palaeoanthropologist who pioneered description of African hominins.}

$\mathrm{P}$ hillip Vallentine Tobias, known to his friends and colleagues as PVT, was the doyen of the palaeoanthropological community. His descriptions of the early hominin fossils found at Olduvai Gorge, Tanzania, are part of the bedrock on which rests our knowledge of human origins.

For half a century, he stewarded the excavations at Sterkfontein, a group of fossil-rich caves northwest of Johannesburg, South Africa. He was a colleague of Louis and Mary Leakey, the husbandand-wife team who did much to establish that humans originated in Africa. And he remained in South Africa throughout his career - with all the professional complications and opportunities for activism that entailed. All this gave him a distinctive role at the University of the Witwatersrand ('Wits') in Johannesburg, and in the field.

Tobias was born and received his early education largely in Durban, South Africa. In the first volume of his autobiography, Into the Past (Picador Africa, 2005), he suggested that the premature death of his sister Val from diabetes, as well as his visits to the Durban Natural Science Museum, were the reasons for his interest in science.

A six-decade-long connection with Wits began when he started his BSc in physiology, histology and embryology, which he gained in 1946. While an undergraduate, Tobias met his mentor, Raymond Dart, who was famous for discovering Australopithecus africanus, the first early hominin to be unearthed in Africa. Tobias completed a medical degree in 1950, but opted for a career in research.

After attaining a $\mathrm{PhD}$ in genetics in 1953, Tobias took part in an expedition to study the San bushmen in the Kalahari Desert. This drew him into physical anthropology. He spent 1955 at the University of Cambridge, UK, examining hominin fossils curated in England and France. In 1956 he toured the United States, returning to South Africa late that year. Through these travelling fellowships he gained contacts that he nurtured for the rest of his career.

In 1959, shortly after Dart retired, Tobias was appointed as head of the anatomy department at Wits, a position he held until he retired in 1990. That was also the year that he got his big scientific break. Louis and Mary Leakey invited him to analyse the Zinjanthropus boisei cranium that Mary had just discovered at Olduvai Gorge (since reclassified as Australopithecus boisei, then as Paranthropus boisei).

Tobias's collaboration with Louis and the British anatomist John Napier to describe the Olduvai fossils became the basis for the description of Homo habilis - a new, and at

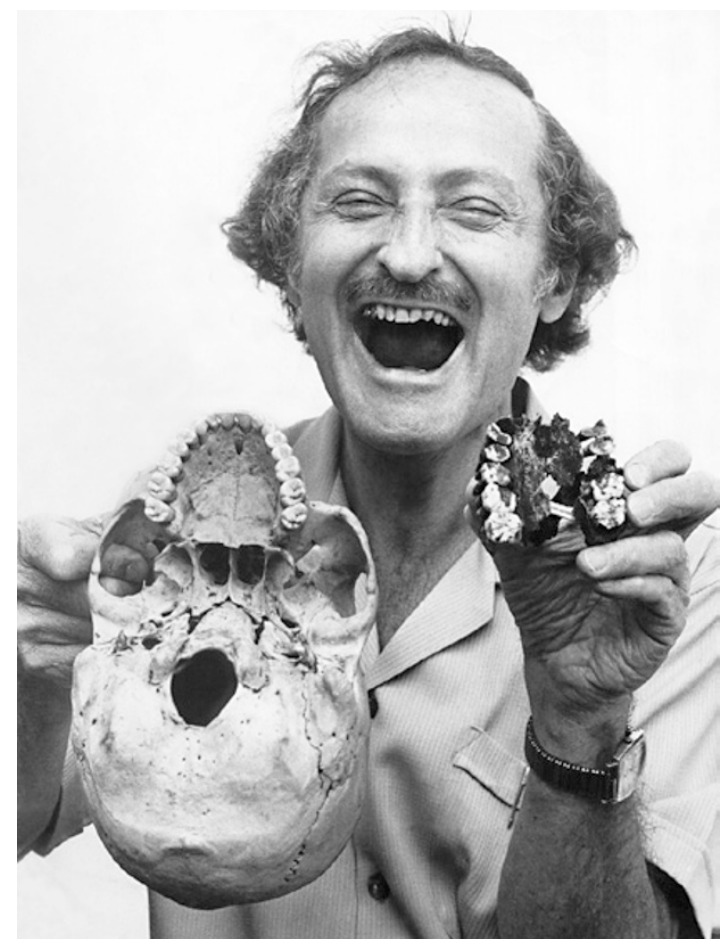

first contentious, hominin species. A monograph, The Cranium and Maxillary Dentition of Australopithecus (Zinjanthropus) boisei (Cambridge University Press, 1967), followed. Two mammoth volumes entitled The Skulls, Endocasts and Teeth of Homo habilis (Cambridge University Press, 1991) provided exquisite details of subsequent hominin discoveries from Olduvai.

For much of his career, Tobias focused on excavations at the Sterkfontein caves. In 1958 Sterkfontein became the property of Wits, and Tobias ramped up the operations there, which continue to this day. Initially, the excavations were supervised by Alun Hughes, who had worked with Dart. Since 1991, they have been led by Ronald Clarke, who had assisted the Leakeys.

By the early 1990s, Tobias's team had collected more than 500 hominin fossils, mostly of $A$. africanus. However, some (including the jaw in his left hand, pictured) were judged by Tobias and Hughes to belong to an early variety of Homo, and Clarke argued that others belonged to Paranthropus robustus. The Sterkfontein fossils are crucial to debates about whether hominins moved freely between eastern and southern Africa, or evolved independently in the two regions.

In 1994, Clarke discovered four australopith foot bones in a box of fossils that had been collected in 1977 . He and Tobias published an account of the bones, and Clarke has since recovered much of the skeleton, nicknamed 'Little Foot'. The collection is on track to being the most complete early hominin skeleton ever recovered.

Tobias's undergraduate contemporaries at Wits' medical school included Sydney Brenner and Aaron Klug. Whereas their research interests led them away from South Africa, Tobias stayed put. He had to remain where the fossils were. He became a consistent thorn in the side of the South African apartheid regime. His vociferous opposition, in speeches and in demonstrations that were ruthlessly suppressed by the authorities, began in 1948 when he became president of the National Union of South African Students. He was no less ardent as a senior academic. Although his scientific prominence gave him a measure of protection, his moral and physical courage was not to be underestimated. It was distressing that Tobias was occasionally tarred with the apartheid brush and denied access to conferences in other countries.

Wedded to his work, Tobias never married. Apart from watching his beloved cricket at the Bidvest Wanderers Stadium in Johannesburg, he either worked or travelled. I visited him once at his home. Even though he owned three large tables, we had to eat dinner from trays on our laps, because his 'habilis volume' was spread out on all the other surfaces.

As meticulous about his manners and dress as he was about his writing and lectures, PVT was kind and encouraging to students and young researchers, me included. South Africa and the palaeoanthropological community are immeasurably poorer for his passing.

Bernard Wood is the University Professor of Human Origins at George Washington University, Washington DC 20052, USA. Tobias became his unofficial mentor after Wood visited Wits to study fossil craniums in 1972. His research builds on Tobias's seminal work on the Olduvai hominin fossil record. e-mail:bernardawood@gmail.com 